http://dx.doi.org/10.12795/PH.1988.v03.i01.10

\title{
LA TRAMA NOVELESCA Y LAS DIGRESIONES EN UNA NOVELA DE ERNESTO SABATO
}

\author{
Trinidad Barrera
}

En 1920, tras los estadios románticos y modernistas, se abre una tercera etapa en el desarrollo del ensayo hispanoamericano, marcada por el signo de la vanguardia. A partir de ese momento, la literatura florecerá especialmente como conocimiento, como «ejercicio de epistemología...; se nos instruye en el escepticismo; la armonía de las esferas será sustituida por cualquier paradoja» ${ }^{1}$. «Maestros» $\mathrm{y}$ «escépticos» podrían ser dos generaciones sucesivas, abiertas, en busca de una nueva autoridad intelectual, «los primeros suelen adoptar como punto de partida la tradición y la historia; los segundos la psicología y la filosofía existencial» ${ }^{2}$. Sería dentro de este segundo grupo, el de los escépticos, donde encajaría la práctica de Ernesto Sábato, al compartir con otros compañeros de generación los tres puntos esenciales del ensayo hispanoamericano de entonces: un nuevo sentido de la identidad nacional de su país, la instrospección vs. desengaño y el cambio de perspectiva de lo particular a lo universal. La Persona se convierte en objetivo preocupante y centralísimo de las reflexiones de estos escritores, si matizamos el concepto con la aclaración del propio Sábato: «A partir de Husserl, sus mejores discípulos ya no centrarán la filosofía en el individuo, que es enteramente subjetivo, sino en la persona, que es síntesis de individuo y comunidad» ${ }^{3}$.

Sábato ha venido alternando el ensayo y la ficción desde 1945. Esta doble combinatoria es un hecho habitual en otros escritores de su tiempo, Borges, Cortázar, García Márquez, Octavio Paz, Alejo Carpentier, etc. Todos ellos

1 P. EARLE: «El ensayo hispanoamericano del modernismo a la modernidad», Revista Iberoamericana, n. ${ }^{\circ} 118-119,1982$, p. 47.

2 EArle y Méad: Historia del ensayo hispanoamericano, de Andrea, México 1973, p. 113.

3 E. SabAto: Obras-Ensayos, Losada, Buenos Aires 1970, p. 559. 
serán «críticos practicantes» en la terminología de Eliot. Los rasgos distintivos formales de cada uno de los autores citados son notables; sus ensayos están visiblemente condicionados por su peculiar imaginación creadora, sírvanos como ejemplo Octavio Paz y su indagación poética de la soledad del ser mejicano en El Laberinto o la ironía juguetona desplegada por Cortázar en La vuelta al día. Los de estos autores son textos, pretendidos ensayos que, como apunta Mignolo para Borges y Paz, se pueden asociar a «los marcos discursivos del ensayo por ser, en primer lugar, prosa expositiva-argumentativa, más que descriptivo-narrativa. Por otra parte, los asociamos a los marcos discursivos de la literatura, sea porque el tema de reflexión es el hacer literario mismo... sea porque en la textura de estas obras encontramos algunas de las características que se manifiestan tanto en su prosa narrativo-descriptiva como en sus poemas» ${ }^{4}$.

La transgresión territorial es bien fácil, las fronteras a veces resultan borrosas, quizás porque el ensayo haya sido con demasiada frecuencia una zona literaria franca en la que han venido a cohabitar el reportaje periodístico, la crítica literaria, la entrevista, e incluso la novela. Es precisamente este último aspecto el que nos interesa aquí, es decir, el complemento de las digresiones o comentarios ensayísticos a la trama novelesca. En Abaddón el exterminador (1974), Sábato lo pone en práctica ahondando en lo que ya había hecho de forma larvaria en novelas anteriores, sin embargo en esta novela la apuesta ha sido más fuerte.

Analizar la crisis de la civilización occidental o el problema de la creación literaria vs. artífice era algo habitual en sus escritos; pero, con escasas excepciones, Sábato lo había practicado de forma generalizada, como autor de numerosos ensayos; ahora incardina en los personajes de su novela y en él mismo como personaje, sus ideas sobre política, arte, filosofía o literatura. Con ello, Sábato está reivindicando para la novela total, como Abaddón, la única posibilidad de síntesis en un mundo escindido por una civilización racionalista y tecnolátrica.

El pensador argentino ha volcado sus vivencias de forma desgarrada en sus obras. Un estudio de su creación permite deducir quién es y qué espera de la existencia. Su producción literaria es fruto de un compromiso del yo con sus criaturas. El autor de El Túnel reconoce que su yo está lleno de contradicciones y dudas, espíritu paradójico y dialéctico que necesita imperiosamente comunicar al público sus contradicciones y perplejidades «y que, por lo tanto - dice él- se manifiesta mejor en la ficción que en el ensayo, ya que en ella puede encarnar en diferentes personajes sus desgarramientos interiores, porque la ficción permite expresar su mundo interior en su enigmática diversidad y unidad» ${ }^{5}$. Si ambas facetas vienen a confluir el resultado podría ser más satisfac-

4 W. Mignolo: «Discurso ensayístico y tipología textual», Textos, modelos, metáforas, Univ. Veracruzana, México 1984, p. 217.

5 E. Sabato: ob. cit., p. 461. 
torio. Por separado, novelas y ensayos forman un sistema de vasos comunicantes que aportan la visión totalizadora de su pensamiento. Como «lo diurno» y «lo nocturno» los calificó en Heterodoxia, al aunarlos en Abaddón se puede cumplir o estar más cerca del compromiso de la verdad total.

Desde Uno y el universo (1945) a Apologías y rechazos (1979), haciendo escala obligada en su confesión de novelista, El escritor y sus fantasmas (1963), Sábato ha ido desbrozando sus conjeturas, obsesiones, miedos, irritaciones, intuiciones lúcidas, etc. siempre balanceándose entre la «apología» y el «rechazo», de forma visceral, polos que no en balde dan título a la última recopilación de artículos, por definir perfectamente el tono de su discurso. Con un estilo irónico, agresivo, brillante incluso, irá poniendo el dedo en la llaga de sus gustos y disgustos, sin importarle la repetición y la insistencia. El proceso de filtración es en su caso más pertinente si cabe y es algo que él no trata de ocultar, con lo cual está dando un paso más a las limitaciones inherentes de todo emisor.

Al enfrentarnos a esta novela surgen dos preguntas: cuál es el material engarzado y cómo se realiza el engarce. Empecemos por lo segundo.

La flexibilidad de buena parte de la novela en los últimos años facilita poderosamente dicho acoplamiento. El caso más estudiado quizá sea el de Cortázar en Rayuela. La digresión en esta novela de Sábato es bastante llamativa, aunque sólo sea en lo relativo al número de páginas. Al igual que ocurre con Cortázar - como ha estudiado Alazraki - los modelos de Musil y Martin Buber resultan los más apropiados. De Musil, científico como Sábato, puede haber tomado la plasmación novelística de las formas del ensayo a través de un proceso de discusión viva, de diálogos candentes más que de razonamientos intelectuales o abstractos. Es éste uno de los objetivos que persigue Sábato, enquistar las ideas en personajes de carne y hueso, ya que como dijo en cierta ocasión «no soy capaz de pensar ideas al estado puro».

En una lectura de Abaddón puede comprobarse cómo el diálogo va a ser el molde más utilizado para la materialización de lo discursivo, ya sea con un fingido periodista, algún personaje de la novela o con su alter ego Bruno, espejo reflector o conciencia dialogal por excelencia. El diálogo, otras veces la epístola, se hace forma, pero también sustancia medular de la obra en el sentido que le da Martin Buber con su empecinada resistencia en no ver el tu como entidad separada del yo, sino complementaria. La novela se convierte así en receptáculo de ideas, gracias al fecundo intercambio entre personajes dentro de la obra.

El conjunto de la producción de Sábato podría representarse a través de círculos concéntricos que mantienen entre sí una relación centrípeta y centrífuga, merced a un doble proceso: absorción y condensación de material anterior y dispersión de este material ya reelaborado y convertido a su vez en nuevo punto de partida. Abaddón puede ser considerada una novela-ensayo debido a su campo situacional que afecta tanto a la intención del autor como al contexto general de comunicación. En lo que respecta a lo primero la obra se presenta como una gigantesca metáfora del mundo planteada caleidoscópicamente a través 
del autor-personaje Sábato y su doble Bruno. Autobiografía personal y espiritual, física y psíquica, se dan la mano con la evocación de recuerdos o memoria real o imaginaria. El contexto de recepción avala también su condición ensayística, ya que el motivo fundamental de Sábato autor es plantear la crisis de la civilización contemporánea, su fin es la intelección y el resultado un libro a caballo entre la autobiografía, las memorias, la sociología y la ficción. Obra cuyo abigarramiento temático se apoya sin dudar en su variopinta estructura, su peculiar andamiaje nos permite calificarla igualmente de libro-collage, ya que al margen de las tres historias principales que urden la trama novelesca, las de Sabato, Nacho Izaguirre y Marcelo Carranza, otras piezas completan el conjunto y son precisamente éstas las que albergan gran parte del material ensayístico. Sirvan como ejemplo los cinco comunicados de Jorge Ledesma a Sabato, dispersos a lo largo del libro, especie de contrapunto psicológico del material novelesco; las conversaciones de Sabato-personaje con los jóvenes de izquierda, Silvia sobre todo, reuniones en las que se discute sobre literatura, revolución, marxismo; o las tertulias en casa de los Carranza, donde la trivialidad de las conversaciones aportan el tono irónico, paródico de un tipo de sociedad en franca decadencia, con rasgos costumbristas.

Estamos, pues, ante un aprovechamiento y expansión de todo un material anterior que cobra nueva vida en esta tercera novela en la que Sábato se descubre como testigo y actitud más que ideología, fundiendo su conciencia individual con la colectiva de sus contemporáneos, con el contexto en que se mueve, de forma fáctica, a través del contacto directo con sus criaturas que es como decir con el hombre de hoy. Sábato cuestiona la literatura escribiendo literatura, se enjuicia a sí mismo enjuiciando su entorno, exorcisa sus demonios conviviendo dolorosamente con ellos.

Si la novela debe ser testimonio de la crisis de la humanidad y a la vez intento de salvación del hombre concreto, la especial forma de esta novela resulta la única posible para revelar la complejidad de los entramados de la existencia. Abaddón engarza su material gracias a un deslizamiento sobre planos espaciales ya sean físicos o metafísicos en estrecha relación con el título mismo. La forma que Sábato adoptó para su discurrir desde Uno y el universo, pensamientos sueltos sobre temas diversos, facilita el engarce de sus ideas en la ficción.

En lo que atañe al material discursivo poca novedad encontraremos. Se podrían comparar los elementos integrantes de El escritor y sus fantasmas con los de Abaddón y veríamos que son básicamente los mismos. El «Interrogatorio preliminar» de El escritor tiene un claro correlato en la novela: «algunas confidencias hechas a Bruno $^{6}$ (p. 25-26) o los datos de su huida a París (p. 131, 263), sus ideas sobre la literatura de introspección (p. 186), las alusiones a sus novelas anteriores o el episodio de los pintores Víctor Brauner y Oscar Domín-

6 E. SÁbAto: Abaddón el exterminador, Alianza Tres, Madrid 1975. Cito por esta edición. 
guez (p. 314-317). En suma, es fácil recorrer los pasos biográficos de Sábato con los datos dispersos a lo largo del libro, datos que no son relatados simplemente sino interpretados a la luz de algunos de los temas-obsesiones del argentino. La ceguera nos llevaría a la historia Brauner-Domínguez; el problema del escritor contemporáneo a la dictomía literatura de instrospección-literatura realista, uno de los dilemas que más agudamente le han preocupado.

Igual ocurre con la parte segunda de El escritor, "Artes y letras en la crisis de nuestro tiempo", esencialmente doctrinaria y destinada a poner de relieve la rebelión del individuo contra la cosificación del universo.

Cuatro aspectos se pueden distinguir en nuestra novela, relacionados todos con sus libros anteriores.

a) El hombre y la crisis de la civilización occidental.Referida al tiempo presente de la novela, Sábato personaje o algún portavoz irá haciendo el desolado balance de una civilización atormentada por plagas sucesivas, epidemias, campos alemanes de concentración, bombas de napalm (p. 89-96); por una escalada ascendente de la violencia (p. 143-156), que enlaza con frecuencia en el hilo de su discurrir con el análisis de la revolución y su validez (p. 264-270), anarquismo (p. 159-170), marxismo (p. 176-194) o el mito del Progreso (p. 205-213). Su óptica es pesimista y desoladora, si no fuera por su fe última en la rebelión del hombre contra el universo cosificado.

b) La creación literaria y el oficio de escritor. Como en el caso anterior reaparecen de forma miscelánea muchos de los puntos de «Características de la novela contemporánea» y «Variaciones sobre el mismo tema» de El escritor. La incomprensión de los contemporáneos hacia el creador, las obsesiones como temas de la escritura, el rechazo al objetivismo según el modelo de Robbe-Grillet (p. 119-138); la novela de hoy (p. 197-213), el estructuralismo (p. 176-194), la «nueva novela» (p. 228-234), la introducción del personaje dentro de la ficción (p. 258), o el dilema literatura política o estetizante (p. 176-194) son alguno de los puntos más frecuentemente analizados. Los resultados no difieren esencialmente de lo que ya dijo en otras ocasiones ${ }^{7}$, pero aquí tiene el atractivo del compromiso estrecho, de haberse sumergido en una ficción novelesca, cuyo protagonista principal no por casualidad se llama Sabato, aunque sea sin acento.

c) Crítica costumbrista de la sociedad. Bajo el calificativo de costumbrismo se podrían señalar aquellas opiniones que el autor vierte sobre la sociedad que le ha tocado vivir y muy especialmente sobre la argentina, su cultura, su literatura; ya sea en su sátira de nombres y apellidos (p. 352-360), el afrancesamiento, el cine, el psicoanálisis (p. 54-60), el espiritismo (p. 275), logias y sectas secretas (p. 78-83) o incluso su mirada burlona sobre la ola de erotismo por aquellos años (p. 364-368).

7 Pueden servirnos de ejemplo «Los fantasmas de Flaubert» (O. E., 865-873) recogidos en esta novela cuando Sabato protagonista escribe a un joven escritor alentándole (p. 125-130); o «Una teoría sobre la predicción del porvenir» (O.E., 889-907) recogida al narrar los episodios de Brauner y Domínguez (p. 314-317); sus teorías sobre Robbe-Grillet, Sartre, etc. 
d) Por último es obligado referirse a sus preocupaciones metafísicas, fin último de sus obsesiones, referidas a Dios y la creación del mundo (p. 54-60), la soledad del individuo, la búsqueda del absoluto, la existencia o la muerte ( $\mathrm{p}$. 478-484) y el Principio (p. 112-113).

Como puede comprobarse todos estos aspectos y subaspectos están referidos al hombre, como apuntó María Angélica Correa, «Toda la obra ensayística de Sábato es una larga, apasionada defensa del hombre concreto» ${ }^{8}$. Hombre escindido entre el deseo de absoluto y la imposibilidad de alcanzarlo.

El fragmentarismo a la hora de exponer sus ideas, visibles no sólo en las estructuras aforísticas de algunos de sus libros de ensayos, sino en la brevedad de sus desarrollos, facilita y enlaza la técnica del collage en Abaddón. La intención polémica también es trasladada a esta obra gracias a que los temas más candentes son discutidos con algún compañero de ficción, a la manera de los diálogos platónicos, resultando conversaciones donde el apasionamiento en la defensa de determinadas ideas o la vibración humana del «crítico» enganchan al lector de forma más directa de lo que pudiera hacerlo la simple exposición abstracta de lo mismo. Su lenguaje es sugestivo, fuerte, lleno de sarcasmos, la relación entre el que habla y de lo que se habla es siempre visceral, el punto de vista personal está comprometido al máximo, suscitando con frecuencia la polémica o la disparidad de opiniones.

La reflexión profunda de Sábato sobre un dominio amplio de temas afecta primordialmente al conocimiento del hombre, fin último de toda su producción, que es casi como decir su vida. Con sus escritos y muy especialmente con esta obra Sábato está ejerciendo una epistemología que propone «la síntesis... de la ciencia y el hombre, el individuo y la colectividad, lo objetivo y lo subjetivo. Debería realizarse en el orden social lo que la nueva filosofía logró en el pensamiento: la síntesis dialéctica del hombre y el mundo» ${ }^{9}$. Con temas intemporales, Sábato puede ser original gracias sobre todo a su desgarrada sinceridad de planteamiento.

8 M. A. Correa: Genio y figura de Ernesto Sábato, Eudeba, Buenos Aires 1971, p. 129.

9 E. SÁBAto: Apologías y rechazos, Seix Barral, Barcelona 1979, p. 133. 